\title{
O sistema de avaliação brasileiro
}

Maria Inês Pestana

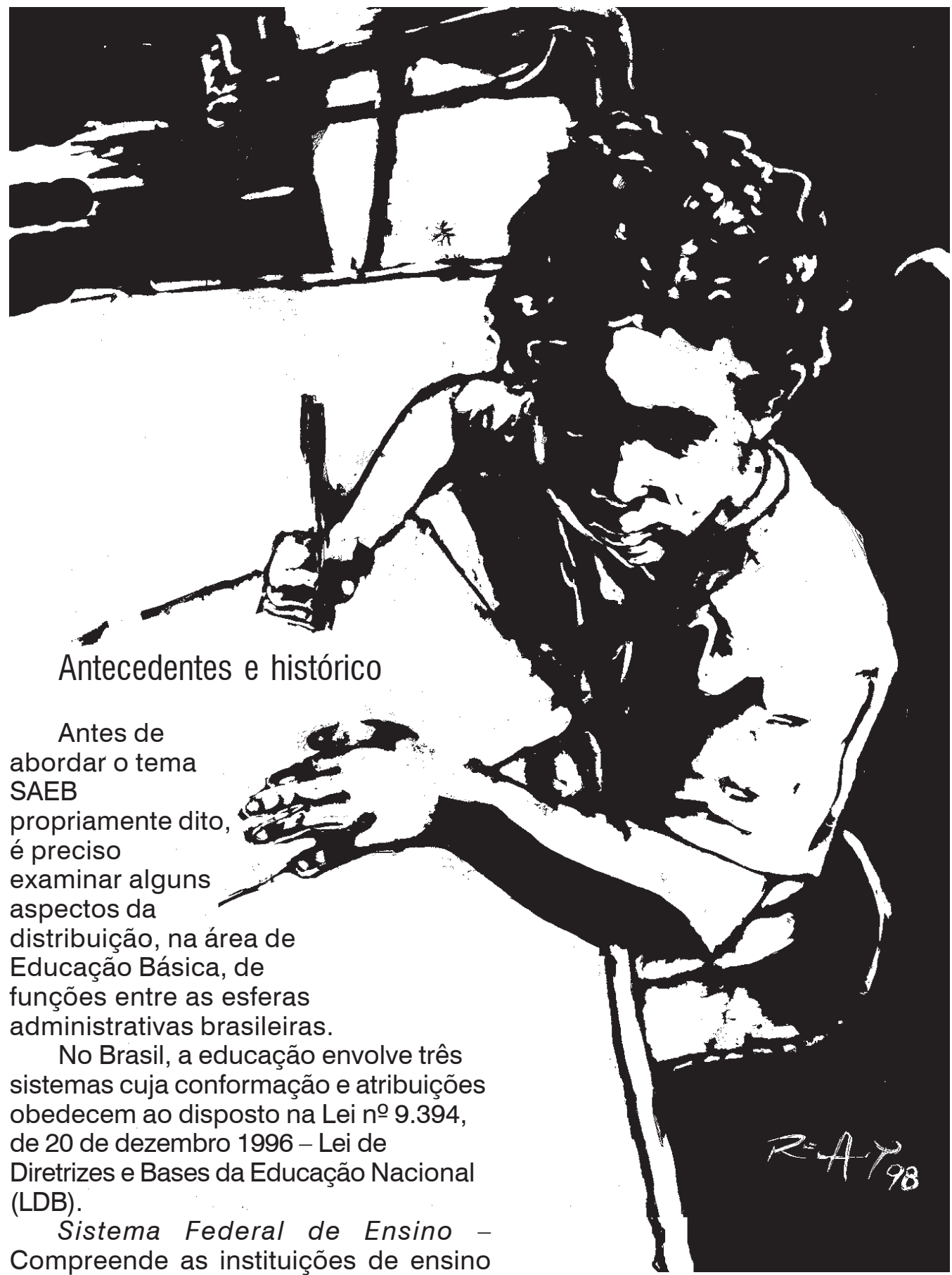


mantidas pela União e os órgãos federais de educação.

Sistemas de Ensino dos Estados e do Distrito Federal - Compreendem as instituições de ensino mantidas pelos Poderes Públicos correspondentes, as instituições de ensino fundamental e médio criadas e mantidas pela iniciativa privada e os órgãos de educação estaduais e do Distrito Federal, respectivamente.

Sistemas Municipais de Ensino - Compreendem as instituições de ensino fundamental, médio e de educação infantil mantidas pelo Poder Público municipal, as instituições de educação infantil criadas e mantidas pela iniciativa privada e os órgãos municipais de educação.

As atribuições desses sistemas foram estabelecidas nos artigos 9ㅇ, 10 e 11 da LDB. No que se refere ao tema deste ensaio, à União compete: elaborar o Plano Nacional de Educação; estabelecer, em colaboração com os Estados, o Distrito $\mathrm{Fe}$ deral e os Municípios, competências e diretrizes para a educação infantil, o ensino fundamental e o ensino médio, que nortearão os currículos e seus conteúdos mínimos, de modo a assegurar formação básica comum; coletar, analisar e disseminar informações sobre a educação; assegurar processo nacional de avaliação do rendimento escolar no ensino fundamental, médio e superior, em colaboração com os sistemas de ensino, objetivando a definição de prioridades e a melhoria da qualidade do ensino.

À União, por intermédio do Ministério da Educação, compete, portanto, a formulação das grandes diretrizes para o sistema educacional e, destacadamente, a ação supletiva, num país de grande dimensão territorial e de grandes desigualdades socioeconômicas. A função supletiva deve ser cumprida no sentido da redução das desigualdades existentes no Brasil. Talvez seja esta uma das funções mais importantes do Ministério da Educação e do Desporto.

A proposta de instituição de um sistema de avaliação surgiu, no Ministério da Educação, durante o período de redemocratização do País, logo no início da Nova República, em 1985/1986. Discutia-se, naquele momento, a questão federativa, a redefinição dos papéis e as atribuições dos diversos níveis de governo exis- tentes no Brasil e, também, o sentido da cooperação, da articulação, da integração e da parceria entre as instâncias de governo. Tais questões, por vários motivos, permaneceriam em debate até o final do década seguinte.

O debate sobre o processo de democratização do País refletia-se, portanto, na educação como discussão sobre a democratização do ensino. Dois aspectos ganhavam relevância.

O primeiro relacionava-se com o acesso à escola. Reconhecia-se que o País tinha feito um grande esforço de construção de escolas e tinha, realmente, ampliado bastante o número de pessoas que ingressavam no sistema de ensino. Os resultados gerados, porém, não eram (ou pelo menos havia uma impressão geral de que não pareciam ser) os desejados. Nada tinha sido medido, mas havia uma percepção muito forte de que era preciso implementar a qualidade do sistema educacional - mas que qualidade?

A qualidade do ensino era a segunda questão crítica do debate sobre a democratização do País e de sua Educação. Isso era o que um sistema de avaliação, paralelamente a outros problemas, deveria tentar examinar. Ficou claro, então, que um sistema nacional de avaliação poderia trazer informações úteis sobre: o que estava sendo gerado no setor educacional, como, onde, quando e quem era responsável pelo produto obtido.

Foi dessa forma que surgiu o Sistema Nacional de Avaliação da Educação Básica (SAEB), como uma atribuição do Ministério da Educação e do Desporto, com o objetivo de coletar informações sobre a qualidade dos resultados educacionais, sobre como, quando e quem tem acesso ao ensino de qualidade.

\section{Características do sistema nacional de avaliação}

O SAEB nasceu da necessidade de articulação, de construção de consenso e de tomada de decisões coletivas a respeito dos rumos da educação nacional. Desde o início, portanto, o objeto do SAEB foi o sistema nacional de educação, ou seja, um tema que diz respeito a toda a socie-

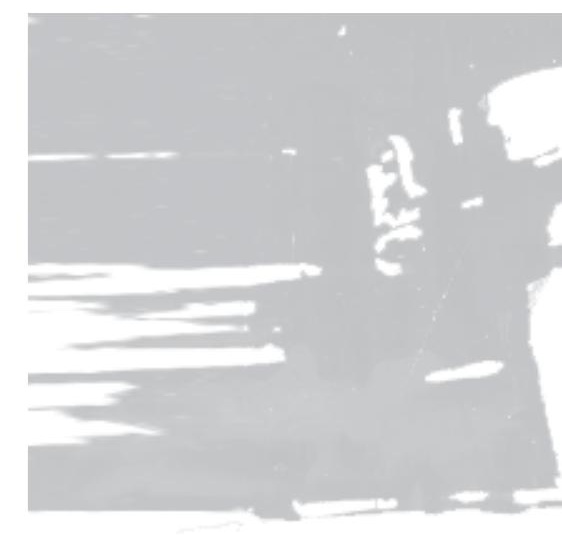


No SAEB, parte-se do princípio de que o desempenho do aluno sofre múltiplos condicionamentos, os quais devem ser considerados pela avaliação. Para tanto devese somar ao desempenho do aluno, pelo menos, mais três dimensões, quais sejam: a determinação de contextos em que ocorrem o ensino e a aprendizagem; a identificação de processos de ensino e aprendizagem e, por fim, o dimensionamento dos insumos utilizados.

A inclusão destas dimensões é fundamental, por exemplo, para determinar a eqüidade na oferta educacional. Quando os insumos estão bem distribuídos e as esco- las têm o mesmo padrão de infra-estrutura ou um padrão semelhante, pode-se afirmar que a população está tendo as mesmas oportunidades educacionais. Indo além e examinando em que medida a oferta de oportunidades semelhantes gera resultados diferenciados e quais as possíveis razões da diferenciação, pode-se determinar até que ponto os bons serviços educacionais estão sendo efetivamente democratizados, isto é, se pelo menos a maioria dos alunos têm, de fato, garantido o direito à educação de qualidade.

Para coletar informações sobre cada uma das três dimensões abrangidas pelo

Quadro 1 - Sistema Nacional de Avaliação da Educação Básica (SAEB)

\begin{tabular}{|c|c|c|c|}
\hline ENFOQUE & DIMENSÃO & INDICADOR/VARIÁVEL & INSTRUMENTO \\
\hline \multirow{3}{*}{$\begin{array}{l}\text { Acesso ao } \\
\text { Ensino } \\
\text { Básico }\end{array}$} & Atendimento & $\begin{array}{l}\text { - Taxas de acesso } \\
\text { - Taxas de escolarização }\end{array}$ & \multirow{2}{*}{$\begin{array}{l}\text { - Questionário do } \\
\text { Censo Escolar do } \\
\text { SEEC/INEP/MEC }\end{array}$} \\
\hline & Eficiência & $\begin{array}{l}\text { - Taxas de produtividade } \\
\text { - Taxas de transição } \\
\text { - Taxas de eficiência interna }\end{array}$ & \\
\hline & Produto & $\begin{array}{l}\text { - Desempenho do aluno, } \\
\text { em termos de: } \\
\text { - Aprendizagem de conteúdos } \\
\text { - Desenvolvimento de } \\
\text { habilidade e competências }\end{array}$ & $\begin{array}{l}\text { - Questões de } \\
\text { provas }\end{array}$ \\
\hline \multirow[t]{3}{*}{$\begin{array}{l}\text { Qualidade, } \\
\text { Eficiência, } \\
\text { Eqüidade } \\
\text { do Sistema } \\
\text { de Ensino } \\
\text { Básico }\end{array}$} & Contexto & $\begin{array}{l}\text { - Nível socioeconômico dos alunos } \\
\text { - Hábitos de estudo dos alunos } \\
\text { - Perfil e condições de trabalho } \\
\text { dos docentes e dos diretores } \\
\text { - Tipo de escola } \\
\text { - Grau de autonomia da escola } \\
\text { - Matriz organizacional da escola }\end{array}$ & \multirow{2}{*}{$\begin{array}{l}\text { - Questionário para: } \\
\text { · alunos } \\
\text { - professores } \\
\text { diretores }\end{array}$} \\
\hline & Processo & $\begin{array}{l}\text { - Planejamento do ensino } \\
\text { e da escola } \\
\text { - Projeto pedagógico } \\
\text { - Relação entre conteúdos } \\
\text { propostos/ensinados e } \\
\text { conteúdos ensinados/aprendidos. } \\
\text { - Utilização do tempo pedagógico } \\
\text { - Estratégias e técnicas de ensino } \\
\text { utilizadas }\end{array}$ & \\
\hline & Insumo & $\begin{array}{l}\text { - Infra-estrutura } \\
\text { (adequação, manutenção e } \\
\text { conservação): } \\
\text { - espaço físico e instalações } \\
\text { - equipamentos } \\
\text { - recursos e materiais didáticos }\end{array}$ & $\begin{array}{l}\text { - Questionário sobre } \\
\text { condições da escola }\end{array}$ \\
\hline
\end{tabular}

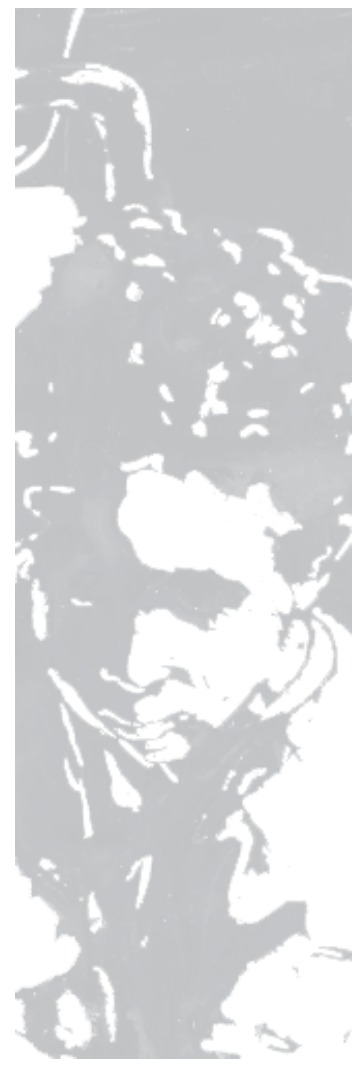




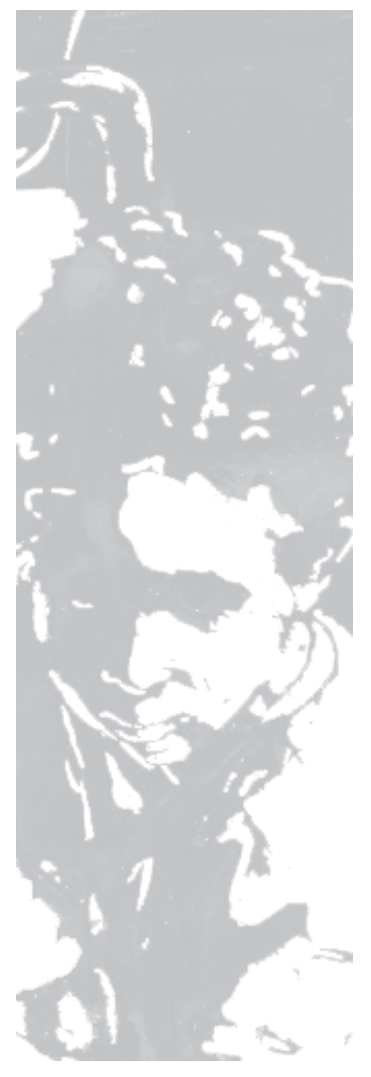

SAEB, foram desenvolvidos instrumentos e procedimentos específicos:

1. A dimensão produto é examinada por meio da aplicação de provas que medem o nível de competência e/ou habilidades que os alunos brasileiros apresentam ou demonstram possuir.

2. As dimensões contexto, processo e insumos são examinadas por meio da aplicação de questionários aos professores (sobre a prática docente, o perfil profissional e as condições de trabalho), aos diretores (também sobre o perfil, a prática e as condições de trabalho) e aos alunos (sobre nível socioeconômico e hábitos de estudo). Além disso, é feito um levantamento sobre as condições das escolas (instalações, equipamentos e materiais disponíveis).

As informações resultantes destes levantamentos permitem fazer associações, correlações, análises hierárquicas e estudos relativamente complexos sobre a realidade educacional brasileira.

O quadro da página anterior apresenta o arcabouço do Sistema Nacional de Avaliação da Educação Básica.

Este é, portanto, o esquema básico da avaliação, que pouco mudou desde que começou a ser desenvolvido.

Quanto à abrangência, o sistema envolve a participação de todas as 27 unidades da Federação, de 2 mil escolas de todas as redes de ensino (federal, estadual, municipal e particular). Em 1998, foi utilizada uma amostra de aproximadamente 220 mil alunos, devendo chegar, a partir de 1999, a cerca de 300 mil alunos, 3 mil diretores e cerca de 20 mil professores.

O esquema amostral compõe-se de amostras probabilísticas de alunos e de amostras relacionadas, ou seja: os alunos que são selecionados para participar do sistema de avaliação têm a mesma probabilidade de seleção, e seus professores e seus diretores são automaticamente selecionados para responder aos questionários. Com isso, estrutura-se uma base de dados que permite as análises e os estudos já mencionados.

Não foi fácil começar o sistema nacional de avaliação utilizando-se provas únicas, aplicadas em todo o território nacional. Na primeira avaliação (primeiro ciclo do SAEB), houve a participação de 23 estados. Somente em 1995, todos os esta-

dos brasileiros e todas as redes de ensino passaram a participar, voluntariamente, do Sistema Nacional.

O SAEB começou avaliando as séries

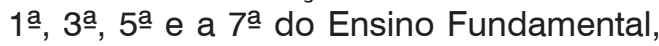
com base em conteúdos mínimos comuns. Para defini-los, fazia-se um levantamento dos currículos estaduais, procurando-se identificar os aspectos comuns (era considerado comum o que aparecia em, pelo menos, $70 \%$ dos estados), e, mediante discussões com as equipes técnicas dos estados, eram definidos os conteúdos que seriam avaliados por meio das provas. Os demais instrumentos, isto é, questionários para diretores, professores e sobre a escola, também foram discutidos, incorporando-se as sugestões das equipes estaduais. Esta busca de consenso é um traço característico do SAEB, e por meio dela o SAEB adquiriu pertinência e legitimidade.

Sobre essa mesma base, realizaram-se os levantamentos de dados nos ciclos de 1990 e 1993.

Em 1995, foi feita uma avaliação externa do próprio $S A E B$, que trouxe à tona algumas questões que implicaram uma mudança metodológica no sistema de avaliação:

A primeira questão relacionava-se aos conteúdos mínimos comuns, que eram a referência das provas. Na realidade, os conteúdos eram mínimos para um ciclo de estudos e não para a série em que eram aplicadas as provas. Por exemplo: parte do conteúdo da 1 a série do Ensino Fundamental que era comum a todos os estados poderia aparecer em cinco estados na 1 a série e em outros cinco na $2^{2}$ série, ou em outra série. Dessa forma, havia um viés que distorcia os resultados da prova, já que os alunos estavam em diferentes condições de aprendizagem: uns foram expostos aos conteúdos, outros não.

Para superar essa dificuldade e também para acompanhar uma tendência do desenvolvimento curricular, passou-se a avaliar as séries finais de ciclos. Os três ciclos avaliados são os seguintes: as primeiras quatro séries do Ensino Fundamental (1a a 4aㅡ), as outras quatro séries do Ensino Fundamental ( $5^{\mathrm{a}}$ a ${ }^{\mathrm{a}}$ ) e as três séries do Ensino Médio ou secundário. Com esta alteração, passouse a examinar conteúdos que cobrem praticamente todo o espectro curricular das propostas de Ensino Fundamental e Médio ou de Educação Básica no Brasil. 
A segunda alteração metodológica, realizada em 1995, foi na maneira de medir o desempenho do aluno. Nesse caso, a metodologia e as provas utilizadas até então tinham muitas limitações. Eram aplicadas provas clássicas de conteúdo, de 30 questões que, por exemplo, não podiam ser comparadas no tempo e tampouco entre as diferentes séries. Por isso, iniciou-se o processo de elaboração e interpretação de escalas de proficiência, construídas com base na Teoria de Resposta ao Item. Esta técnica permite os dois tipos de comparação (no tempo e entre séries), pois a unidade de análise passa a ser o item da prova, e não mais a prova completa, nem o aluno.

O uso da Teoria de Resposta ao Item e das Escalas de Proficiência associado a uma técnica de balanceamento de conteúdos permitiu, também, a superação de uma terceira dificuldade: a pequena amplitude de conhecimentos inerentes a uma prova de 30 questões. O SAEB de 1995 utilizou cerca de 150 questões em cada uma das disciplinas avaliadas. Embora cada aluno continuasse respondendo entre 30 e 35 questões, foi possível avaliar o desempenho do grupo de alunos em todas as 150 questões utilizadas, cobrindo, portanto, um espectro mais amplo do currículo.

Até este momento, o SAEB avaliou os alunos em Matemática, Língua Portuguesa e Ciências; nesta última, a partir de 1997. Para 1999, foi decidida a ampliação do sistema à História e à Geografia.

Um grande esforço tem sido feito para manter a transparência da avaliação e para torná-la amplamente conhecida. Embora os instrumentos que examinam os fatores associados ao desempenho sejam conhecidos de todos, por questões técnicas, ainda não é possível dar a conhecer as questões das provas. Buscando minimizar esta impossibilidade, iniciou-se um trabalho interessante, e de certa maneira inovador, que é a elaboração da matriz curricular de referência para avaliação.

Essa matriz é quase uma tabela de especificação para a elaboração das questões das provas do SAEB. Para elaborar essa matriz, o procedimento utilizado foi o mesmo de quando foram definidos os conteúdos mínimos comuns. Novamente, buscouse tudo o que havia de comum nas propostas curriculares dos estados para os três ciclos de ensino. Foram incorporadas as propostas dos Parâmetros Curriculares Nacionais, elaboradas pelo Ministério da Educação e que servem de referência para o País, e também foram considerados os "estados da arte" de cada disciplina e os níveis de desenvolvimento cognitivo associados aos ciclos de ensino. Mais uma vez, todo o material elaborado foi encaminhado para críticas e sugestões das equipes das Secretarias de Educação dos estados.

A matriz de referência para a avaliação apresenta uma série de descritores do desempenho do aluno. Cada descritor é um cruzamento ou associação entre conteúdos curriculares e operações mentais (competências e habilidades). Nisso residem a ousadia e a dificuldade do trabalho tal como tem sido realizado.

A matriz parece ser uma maneira de superar a divisão, perceptível em quase toda proposta curricular, entre os objetivos curriculares e a lista de conteúdos, pois concretiza, em cada descritor, a articulação entre objetivo curricular (ou objetivo de desenvolvimento) e o conteúdo. Segundo diversos depoimentos de professores, a matriz, de fato, conseguiu descrever, em cada descritor, o desempenho desejado do aluno, ou seja, que operação mental o aluno deve realizar em relação a cada conteúdo.

Ao final de 1998, todo o trabalho continuava em discussão. As matrizes de referência para a avaliação, por exemplo, devem cumprir dois objetivos: dar transparência à avaliação e diminuir um dos maiores riscos desta, que é o da redução daquilo que é ensinado ao que é avaliado. Por isso, o desenvolvimento das matrizes associado à utilização de modelos da Teoria de Respostas ao Item para análise e construção de escalas de desempenho permite que se faça uma descrição bastante ampla daquilo que se espera que seja desenvolvido e atingido, ou esteja sendo alcançado pelos alunos.

Completando a descrição das matrizes, resta dizer que ela organiza os descritores de desempenho em tópicos, temas e assuntos (conteúdos) e operações mentais (competências e habilidades) distribuídos em três ciclos (até a $4^{\text {a }}$ série do Ensino Fundamental, até a $8^{a}$ do Ensino Fundamental e até a $3^{\text {a }}$ série do Ensino Médio) e três categorias: competências básicas, operacionais e globais, isto é, em

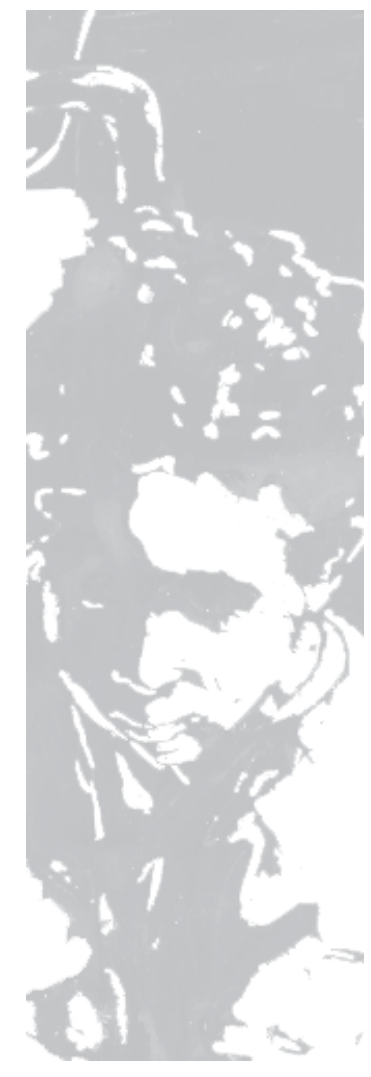




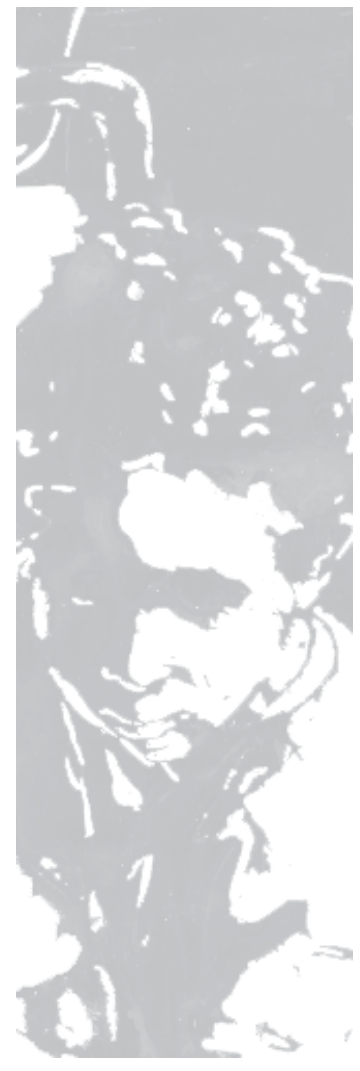

cada um dos ciclos aparecem as três categorias de competências.

Após realizar a coleta e a análise dos dados, o Sistema Nacional de Avaliação da Educação Básica (SAEB) informa à sociedade os resultados mais gerais e coloca à disposição de administradores, gestores, professores, diretores de escolas, alunos, especialistas, uma série de informações que permitem uma observação qualitativa do sistema de ensino.

Em relação ao desempenho dos alunos, são fornecidos dois tipos de informação: primeiramente, as médias de proficiência, que é uma informação geral sobre a capacidade do aluno, isto é, aquilo que os alunos de cada uma das três séries avaliadas são capazes de fazer. Essa informação baseia-se na escala de proficiência construída para o País, que interpreta e sintetiza o desempenho dos alunos. Essas informações podem ser obtidas desagregadas por região e por estado, rede de ensino, localização, características dos alunos, professores, diretores e das escolas; em segundo lugar, os resultados de aproveitamento médio do aluno, isto é, qual foi o comportamento dos alunos, em relação a cada um dos descritores de desempenho que constam das Matrizes de Referência da Avaliação bem como ao seu conjunto, sendo, portanto, uma informação de cunho curricular bastante detalhada. Esses dados permitem a realização de análises sobre o currículo aprendido e seu aperfeiçoamento.

Todas as demais informações sobre variáveis associadas ao rendimento escolar e de caracterização das escolas, alunos, professores e diretores também são acessíveis aos interessados.

\section{0 debate sobre 0 sistema nacional de avaliação hoje}

No estágio de desenvolvimento em que se encontrava o SAEB no momento da elaboração deste trabalho, uma grande questão começava a ser debatida: até onde vai a real capacidade de um sistema nacional de avaliação de informar sobre todos os aspectos relacionados à educação e sobre a diversidade e a singularidade das escolas?
Apesar de todo esforço realizado no desenvolvimento do sistema, da legitimidade obtida, da parceria estabelecida com os sistemas de ensino, e embora a avaliação tenha sido progressivamente apropriada pelos sistemas de ensino, um sistema nacional de avaliação não responde, nem poderia responder a todas as necessidades de informação. Tampouco tem capacidade de apreender toda a diversidade e singularidade das escolas. Por isso, tem de ser complementado.

A luz que o SAEB lançou sobre o sistema de ensino e as escolas não foi suficiente, por exemplo, para iluminar o que acontecia em sala de aula. Neste e em outros aspectos, seria preciso que estados, municípios e escolas promovessem a realização de estudos e pesquisas que sustentassem o desenvolvimento de sistemáticas de avaliação capazes de informar sobre questões mais específicas e singulares a cada instância. Essas avaliações poderiam ter um caráter complementar ao sistema de avaliação nacional, tanto em termos de objeto quanto em termos conceituais e metodológicos.

À medida que aumentou a utilização das informações do SAEB, ampliando-se os usuários da informação e, talvez por isso, surgiram muitas questões para as quais o SAEB não podia fornecer elementos. Esta impossibilidade gerou críticas ao sistema de avaliação, sendo a principal delas a que via como falha do sistema o fato de que não fossem encaminhados resultados da avaliação às escolas. Em conseqüência disso, as escolas fariam pouco ou nenhum uso dos dados da avaliação nacional.

Embora essa crítica tivesse fundamento e fosse desejável devolver os resultados da avaliação às escolas, seria preciso discutir alguns outros aspectos que também compõem o quadro da avaliação nos estabelecimentos de ensino.

Primeiramente, como a avaliação não era um fim em si mesma e sim um instrumento a ser utilizado para corrigir rumos, parecia ser muito importante assegurar que, juntamente com as informações obtidas pela avaliação, fossem criados e utilizados recursos que pudessem ser empregados na superação dos problemas diagnosticados, ou a reafirmação das medidas e práticas bem-sucedidas. 
Deve haver uma ponte entre a avaliação e a ação. Ou seja, não basta informar ou iniciar um processo de reflexão na escola, seus problemas ou deficiências, sem colocar à sua disposição os recursos de que precisa para superar suas dificuldades, pois nesse caso a avaliação tende a exercer somente o papel cruel, inútil e vazio de testemunha, e não de agente transformador e pró-ativo.

Ser informada, portanto, é condição necessária, mas não suficiente para que as escolas utilizem dados de avaliações. À informação deve-se somar o conhecimento e a capacidade técnica para lidar com a informação, a autonomia para decidir e os recursos para implementar as decisões tomadas. Caso esses três elementos não existam na escola, a informação da avaliação será abandonada, na melhor das hipóteses.

Outra possibilidade, mais pessimista, é que a avaliação, na medida em que as intervenções propostas não sejam coerentes com o diagnóstico da avaliação, isto é, não tenha seus resultados incorporados na linha de atuação da escola e das secretarias estaduais e municipais de educação, passe a exercer um papel paralisante e desestruturador da ação educacional, gerando mais impasses do que soluções. A capacitação de professores pode ser um exemplo deste tipo de situação. Caso a avaliação mostre que há problemas de aprendizagem em determinados conteúdos de Matemática, seria desejável que fossem oferecidas capacitações de professores relacionadas a esse aspecto.

Por esses motivos, parecia ser mais prudente que os resultados da avaliação nacional chegassem às escolas mediados pelos estados e municípios, que poderiam, assim, estabelecer os vínculos e a coerência entre o diagnóstico e suas linhas de ação.

Além do uso dos resultados da avaliação pelas escolas e pelos sistemas de ensino, existe um outro usuário das informações da avaliação que deve ser destacado. Trata-se da sociedade, que, por meio do SAEB, conta com um instrumento de controle social de um serviço público. Por meio do sistema de avaliação, a sociedade é informada sobre os resultados obtidos pelos diferentes sistemas de ensino, sobre as diferentes condições de oferta de educação e sobre as diferenças e as desi- gualdades educacionais existentes no País. Nesse caso, a utilização de tais informações tem um cunho eminentemente políti$\mathrm{co}$, de fortalecimento do jogo democráti$\mathrm{co}$, ao gerar pressão social tanto para correção das distorções e superação dos problemas quanto para a preservação de conquistas e ganhos.

Considerando a descentralização, a desconcentração e a autonomia da escola como tendências irreversíveis do nosso sistema educacional, o sistema nacional de avaliação reveste-se de fundamental importância para servir como referência a esse sistema descentralizado e autônomo e reduzir o risco de desarticulação e pulverização dos objetivos do sistema educacional. Isto é, o SAEB.

Ao fornecer informações sobre os resultados que vêm sendo obtidos no País, nas regiões, nos estados e nas escolas, 0 sistema tem permitido que a população avalie a escola que freqüenta, informandose sobre a qualidade do ensino que lhe é oferecido.

\section{Considerações finais}

O desenvolvimento de sistemas nacionais de avaliação é um fenômeno bastante recente, e por isso mesmo, pouco analisado em sua diversidade e limites. De maneira geral, são apresentados como instrumentos de gestão do sistema escolar. Sob esse ponto de vista, são recursos poderosos e arriscados, na medida em que sinalizam padrões de aprendizagem que a escola básica deve assumir como seu objetivo, mostrando se os ganhos de qualidade do sistema educacional estão socialmente bem distribuídos.

$\mathrm{O}$ caso brasileiro não é diferente. $\mathrm{O}$ SAEB tem se revelado um instrumento para a superação de uma das falhas mais flagrantes do sistema educacional hoje, qual seja: as escolas não têm clareza sobre onde devem chegar e, muitas vezes, nem sabem de que bases partem.

O caminho escolhido para a identificação destes objetivos foi o da negociação, da transparência e do debate. Por isso, o SAEB vem assegurando o cumprimento dos seguintes princípios ou diretrizes no seu processo de desenvolvimento técnico e institucional:

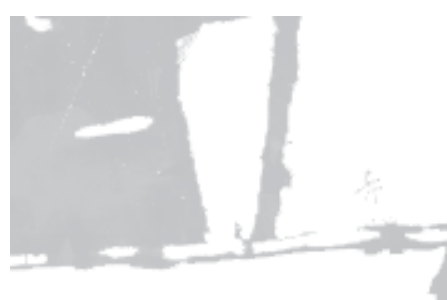




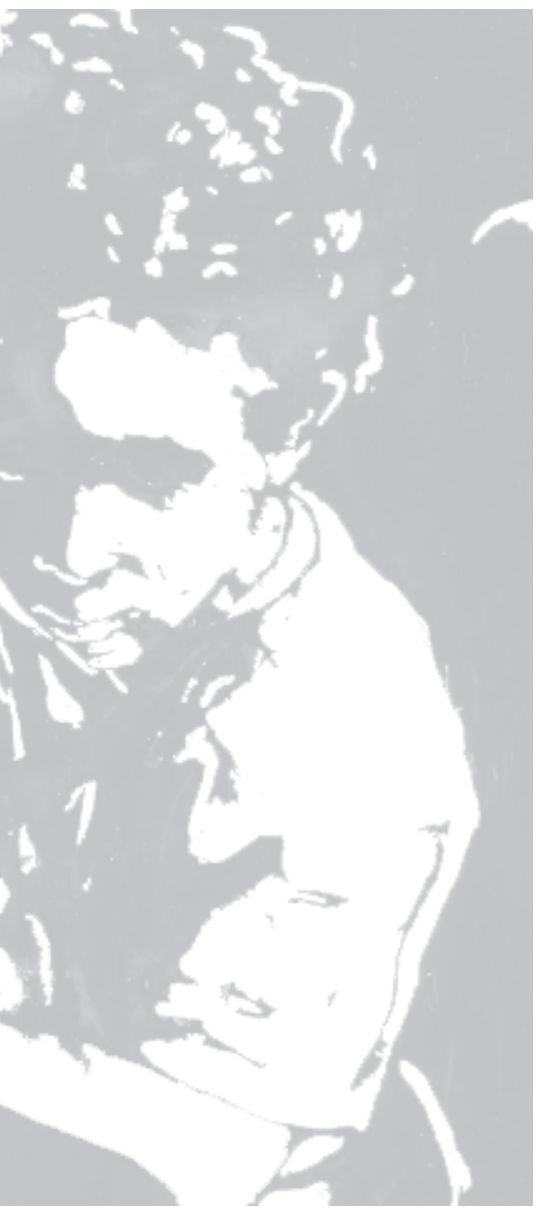

1. Visibilidade social: identificando e apresentando para gestores, administradores, professores, pais e alunos os resultados e produtos obtidos pelo sistema de ensino.

2. Responsabilização: procurando identificar a parcela de contribuição de cada segmento envolvido na obtenção dos resultados do processo educacional, o que induz ao comprometimento com a busca e a implementação de ações corretivas e de aperfeiçoamento.

3. Desenvolvimento de competência técnico-científica: sendo fundamental a capacitação de recursos humanos para o desenvolvimento e o fortalecimento da competência avaliativa nos sistemas educacionais.

4. Estabelecimento de parcerias: entre o Ministério da Educação, sistemas de ensino, universidades e instituições de pesquisa para o desenvolvimento e a execução dos projetos de avaliação.
5. Utilização dos resultados: para a formulação e a reformulação de políticas, programas e projetos educacionais, de maneira a ampliar (e mesmo induzir, em alguns momentos) a reflexão sobre questões da qualidade dos resultados e sobre a atuação de todos os envolvidos no processo educacional (gestores, professores, pais, alunos e educadores).

Em síntese, o SAEB vem gradativamente apresentando elementos que permitem identificar as significativas diferenças que existem entre o que a sociedade espera como resultado do processo escolar, o que é possível dele esperar e o que efetivamente dele resulta, em termos de desenvolvimento, nos alunos, de competências básicas, capacidade de pensar e qualidades pessoais, isto é, a contribuição da escola para o desenvolvimento da cidadania.

Esse é o rumo e esse tem sido o grande desafio.

Maria Inês Pestana é diretora da DAEB (Diretoria de Avaliação da Educação Básica), do INEP, e responsável pela coordenação do SAEB (Sistema Nacional de Avaliação Básica).

\section{Resumo}

Descreve a evolução do Sistema Nacional de Avaliação da Educação Básica (SAEB), desde as discussões que antecederam sua criação em 1988. Além de rever criticamente o debate sobre a natureza de um sistema nacional de avaliação compatível com a realidade e as necessidades brasileiras, apresenta as mudanças ocorridas no SAEB em termos de metodologia e discute a relação entre avaliação e ação no Ensino Fundamental Brasileiro. Na conclusão, são apontados os princípios e diretrizes erigidos pelo Sistema, como instrumentos do desenvolvimento educacional do País.

Palavras-Chave: SAEB, avaliação do ensino, educação básica.

\section{Abstract}

This work portrays the development of the National System for Evaluation of Basic Education (SAEB) since the discussion that precede its creation in 1988. Besides, it critically review the debate on the nature of the National Evaluation System compatibility with the Brazilian necessities. The work also presents the methodology changes in SAEB, as well as the discussion about the relationship between evaluation and action in Basic Education in Brazil. In conclusion, it indicates the principles and guidelines raised by the System as the country's educational development instruments.

Key-Words: SAEB, basic education, evaluation in basic education. 